\title{
Analysis of stress pins for the local prestressing of cold forging tools
}

\author{
Martin Killmann $^{1}$ (1) $\cdot$ Marion Merklein ${ }^{1}$
}

Received: 13 October 2020 / Accepted: 7 December 2020 / Published online: 28 December 2020

(c) The Author(s) 2020

\begin{abstract}
The trend towards lightweight design leads to an increasing demand for sophisticated part geometries with high functional integration. In order to use the advantages of cold forging regarding the time- and resource-efficient production of highquality parts, high local stresses causing fatigue failure in geometrically complex tools have to be controlled. The objective of this manuscript is to analyse the use of stress pins for a local influence on the stress state within forging, especially in non-circular symmetrical cold forging dies. For this purpose, a closed-die forging process for elliptical parts is designed and analysed regarding the die stresses. Distinct areas with local compressive and tensile stresses occur in the process. To counteract the tensile stresses critical for fatigue failure, the effect of stress pins pressed into the die creating a local prestress is analysed. Around the pins, compressive radial and tensile tangential stresses occur. While large pin diameters, interferences and close positioning to the tensile area lead to an increasing prestressing effect, too high values of these parameters cause a detrimental superposition of tensile process and pin stresses. If used correctly, there is high potential to improve the stress state and tool life especially for locally stressed complex tools.
\end{abstract}

Keywords Cold forging $\cdot$ Die design $\cdot$ Tool load $\cdot$ Local prestressing $\cdot$ Stress pins

\section{Introduction}

Cold forging enables the economic and ecological mass production of high-precision metal parts [1]. As the flow stress of the formed material is not reduced by heating, high forming loads causing contact pressures of up to $3000 \mathrm{MPa}$ occur in cold forging processes [2]. These contact pressures place heavy demands on the tools, which take a key role in cold forging due to their direct influence on part accuracy and process economics [2]. Costs for the manufacturing of new tools and machine downtime following tool failure cause up to $30 \%$ of overall costs in cold forging [3]. Tool life is mainly limited by the failure mechanisms wear and fatigue [2]. While wear occurs in areas of high contact pressure and sliding velocities [4], fatigue is caused by cyclic loading with high tensile stresses initiating cracks in the tool material [5]. In order to limit wear, materials used for cold forging tools are often high speed steels or cemented

Martin Killmann

martin.killmann@fau.de

1 Institute of Manufacturing Technology, Friedrich-Alexander-

Universität Erlangen-Nürnberg, Egerlandstraße 13,

91058 Erlangen, Germany carbides, which are very sensitive towards tensile stresses causing fatigue failure [6]. As tensile stress peaks occur at local filigree elements like small radii and sharp transitions of the cross-section [2], nearly all cold forging tools for complex parts fail due do fatigue [7].

While cold forging is conventionally used for the manufacturing of symmetrical parts [8] such as bolts [9] or shafts [10], the production of more complex part geometries like screw wrenches [11], hex flange nuts [12] or gear rings for wheel-shaft assemblies [13] is currently being researched. This has been made possible by developments in materials, coatings and process design [14]. The production of more complex part geometries through cold forging is necessary because of the trend towards lightweight construction, which leads to a demand for more sophisticated parts with a high degree of functional integration [15]. Local tensile stresses and resulting tool failure through fatigue have been identified as challenges for the cold forging of asymmetrical parts [15]. This motivates the research of measures to counteract tool failure in geometrically complex tool geometries. 


\section{State of the art}

According to the strength versus load concept the strength of the tool can either be increased or the occurring stresses reduced in order to counteract fatigue failure [2]. Measures to increase the strength include the use of different tool materials [6], coatings [16], tool production methods [17], or heat treatments [18]. Despite the various approaches, strength can only be increased up to a certain point. For example, cemented carbides, which already cost ten times more than conventional tool steel [19], are still very sensible towards tensile stresses [6]. Therefore, a decrease of the stresses in the die is necessary. One possibility to achieve this is to reduce the load acting on the tool. However, the load results from the forming process [20] and is often seen as a boundary condition for tool life analysis [3]. Because of the high effort necessary to implement process changes, an adaptation of the load through the number and layout of forming steps should only be considered in special cases [3]. Another approach to decrease stresses is to adapt the tool layout, for example by using appropriate radii and sliding lengths [21]. Since changes of the inner tool contour can only be made within the specified tolerances of the produced part, a change in the outer tool contour would be more universally applicable. One approach is to use split tools to reduce bending stresses [1]. This has the disadvantage, that lubricant or workpiece material may enter the split section [22]. To globally reduce tensile stresses, dies are usually prestressed by pressing them into reinforcement rings with an interference closure [23]. For highly stressed parts, stripwound containers are used [24]. With these conventional reinforcement systems, no local influence on the stress state is possible. For a combined tangential and axial prestressing, reinforcement systems with a locally adapted interference closure have been developed [25] and successfully implemented [26]. These systems only have a local influence on axial stresses, not different stresses resulting from non-circular cross-sections.

For a local prestressing of distinct areas in a tool, the use of so-called stress pins has been suggested [27]. Similar to reinforcement rings, stress pins use an interference to create prestresses. The difference is, that stress pins are pressed into the die inducing a local stress from the inside. It has been shown, that stress pins could effectively reduce stresses and deflections in a hydroforming die [27]. When implemented for the precision forging of a connection rod, the resulting stresses were increased with the use of stress pins [27]. Although it was stated, that the effect of the pins should be examined in further detail [28], no new investigations were carried out to date.

\section{Objective and methodology}

The overall objective of this research is to obtain a fundamental understanding for the local prestressing effect of stress pins in order to improve the stress state and increase the tool life of cold forging dies. By analysing cause-effect relations regarding the stress state with varying pin parameters, insights for the appropriate use of stress pins are provided. In order achieve this, the methodology shown in Fig. 1 is applied. For the analysis of stress pins in cold forging tools, a model process with local stress concentrations is necessary. For this purpose, requirements regarding the process setup and components are identified and part as well as tool geometries are derived. The sophisticated analysis of the formation and distribution of the die stresses requires a numerical model. Therefore, a finite element (FE) model of the process is set up with the program simufact.forming 15.0 and validated through the comparison with experimental results. Subsequently, the validated model is applied for an analysis of the stresses occurring during the process. The causes for the local loads as well as the challenges they
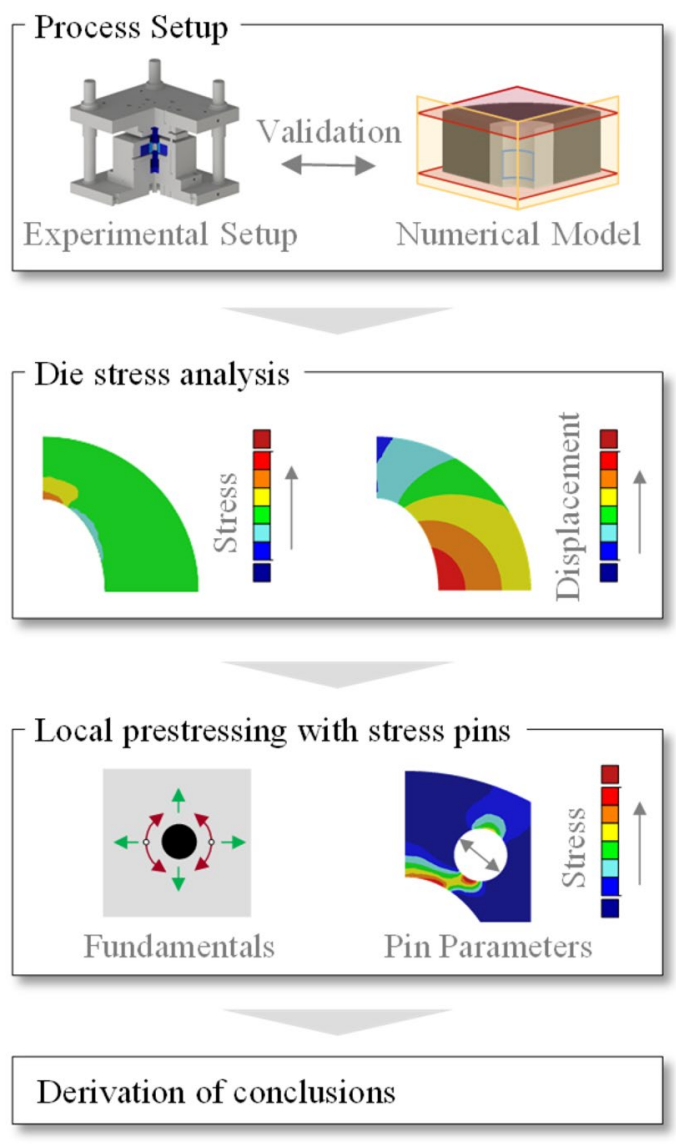

Fig. 1 Methodology to gain understanding for the use of stress pins 
Table 1 Analysed parameters

\begin{tabular}{|c|c|c|c|}
\hline \multicolumn{2}{|l|}{ Pin parameters } & \multicolumn{2}{|l|}{ Pin position } \\
\hline $\begin{array}{l}\text { Interference } \xi \\
(\% \circ)\end{array}$ & Diameter d (mm) & Distance a $(\mathrm{mm})$ & Angle $\beta\left({ }^{\circ}\right)$ \\
\hline 1 & 2 & 1 & 15 \\
\hline 3 & 3 & 2 & 22.5 \\
\hline 5 & 4 & 3 & 30 \\
\hline 7 & 5 & 4 & 37.5 \\
\hline 9 & & 5 & 45 \\
\hline
\end{tabular}

present for the tools are identified. Based on the results, the use of pins pressed into the die is investigated regarding the interaction of pin and process stresses. To gain further insight into the effect of stress pins, the stress state for different diameters, interferences and positioning of the pins is analysed. For the positioning the distance a to the inner die wall and the angle $\beta$ from the critical area are taken into account. The investigated parameters are summarized in Table 1, with the reference values indicated in bold. Finally, conclusions about the influence of stress pins on local loads and challenges for their use are derived.

\section{Experimental setup}

In order to enable the analysis of the local prestressing effect by stress pins, a model process with high local tool stresses is required. Therefore, a closed-die forging process is chosen. Unlike open-die forging, closed-die forging tools do not have a flash gap for superfluous material, thus enabling the production of net-shape parts [29]. This leads to very high contact pressures and tool loads [30]. To ensure a local stress distribution, a non-circular symmetrical part geometry is used. For a fundamental research, elliptical parts with a constant cross-section are formed from cylindrical blanks. The corresponding part geometry and tool layout is shown in Fig. 2.

The shape of the punch and counter-punch as well as the inner contour of the die are identical to the elliptical part. The cylindrical blank is placed on the counterpunch and pressed into the die with a force of approximately $700 \mathrm{kN}$. Assuming complete filling of the die cavity, the part height is reduced from 24 to $16 \mathrm{~mm}$. The die is prestressed by a reinforcement ring with an interference of 3\%. The dimensions of die and reinforcement are chosen in accordance to ICFGguidelines [23]. The tool system is installed into a press type Lasco TSP100S0 with a maximum force of $1000 \mathrm{kN}$. In order to provide practically relevant results, frequently used materials are chosen for the tools and workpiece. The workpiece is made of the steel $16 \mathrm{MnCrS5}$, which is often applied for cold forged products like gears [31]. To reduce
Part geometry

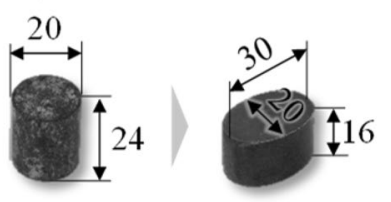

Tool Layout

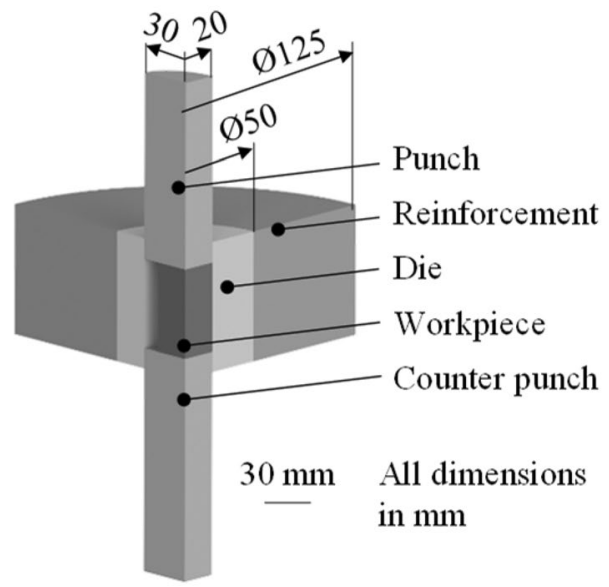

Fig. 2 Part geometry and tool layout of the model process

friction, it is coated with a combination of zinc phosphate layer and the lubricant soap. This lubrication system is commonly used for parts with high surface enlargements [32]. High-speed PM-steels are often chosen for highly stressed cold forging tools [6]. Therefore, ASP 2023 is applied as die material and ASP 2030 as tool material for the punch and counterpunch. For reinforcement rings, commonly used materials include hot-working steels like 1.2344 [6], which is used in the process.

\section{Numerical process model}

The use of FE simulations to map metal forming processes and gain process understanding has been continuously increasing [33]. Simulations enable the analysis of tool loads and stress distributions, which are difficult to analyse in experiments [34]. Therefore, a numerical model of the process is set up.

\subsection{Setup}

The main purpose of the FE simulation is the analysis of the die load with varying tooling concepts. The process is mapped with the software Simufact.Forming 15.0 using a decoupled approach, in which material flow and die loads are calculated separately. This allows for a robust and conclusive analysis, since die loads are not substantially influenced by the feedback between material flow and die load [35]. The 
material flow simulation uses rigid dies with the geometries given in Fig. 2. In metal forming simulations, the workpiece is usually meshed using hexahedral elements to ensure a robust model and reduce computation time [33]. Therefore, hexahedral elements with an edge length of $0.6 \mathrm{~mm}$ are used. The outer area of the workpiece starting at a radius of $9.0 \mathrm{~mm}$ is refined using edge lengths of $0.3 \mathrm{~mm}$. The workpiece material behavior is depicted with the flow curve shown in Fig. 3, which was determined with a compression test according to DIN 50,106 [36]. The material behavior could be measured up to a true strain of 0.5 . For higher values the curve was extrapolated using the Hockett-Sherby approach [37].

For the representation of the friction between workpiece and tools, the friction factor model is used. To determine the friction factor, a double-cup extrusion (DCE) test is performed. This laboratory test realistically reflects the tribological conditions of cold forging especially regarding contact normal stresses and surface enlargement [38]. In the test, a cup is formed by a combined forward and backward extrusion process [38]. The ratio between upper and lower cup height depends on the friction conditions. Therefore, the cup height ratio can be used to numerically identify the friction factor. For this purpose, specimens were formed using the universal testing machine Schenk Trebel 400. To ensure comparable tribological conditions, the materials of workpiece and die as well as the surface finishing and lubricants were the same as in the model process. A cup height ratio of $0.380 \pm 0.004$ was measured for $n=6$ specimen. To determine the corresponding friction factor, simulations of the DCE test with friction factors from 0.01 to 0.08 were conducted in steps of 0.01 . As is shown in Fig. 4, the best agreement of the cup height ratios was reached with the friction factor 0.04 , which is therefore used in the simulation of the model process.

The contact stresses between workpiece and die from the material flow simulation are transferred to the die load simulation. In order to limit simulation time, the symmetry of the process is used, so that only a $90^{\circ}$ segment is calculated. For the analysis, die and reinforcement are taken into

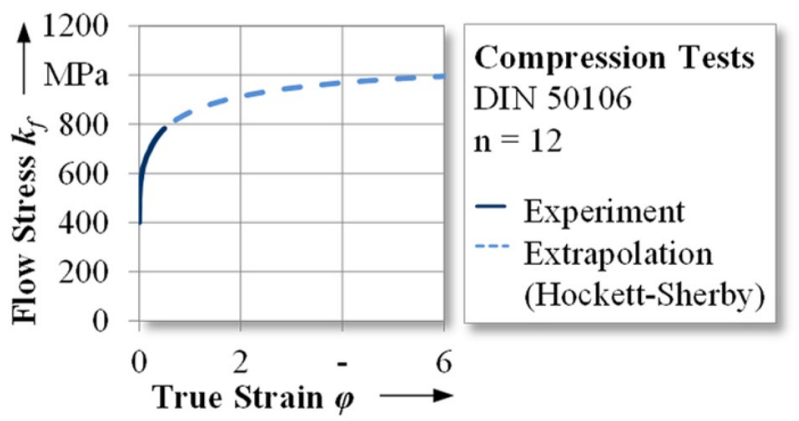

Fig. 3 Flow curve for $16 \mathrm{MnCrS} 5$ from compression tests

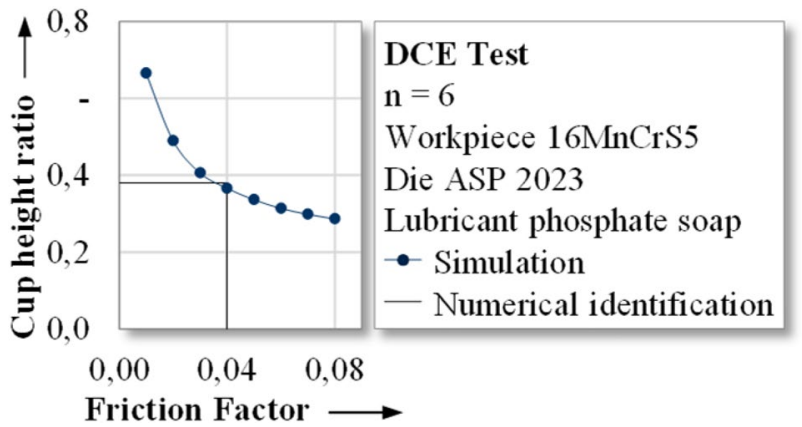

Fig. 4 Numerical identification of the friction factor using DCE-test results

account, since the die is the most critical part in the process and the reinforcement ring influences the stress state of the die. The prestressing between the tools is considered with a physical overlap of $0.075 \mathrm{~mm}$, which corresponds to a relative interference of $3 \%$. Further boundary conditions are considered with the placement of constraint planes on the upper and lower side of the die, see Fig. 5. This enables the fundamental research of the die and reinforcement system without varying external influences. The tool geometries are discretized with a maximum geometrical deviation of $0.01 \mathrm{~mm}$ using tetrahedral elements, since this element type is suitable for the meshing of complex geometries that often occur in tools [33].

\subsection{Validation}

In order to ensure the realistic depiction of the process by the simulation, the model is validated according to TEKKAYA [39]. For this purpose, both process- and componentsided target values are compared between experiment and simulation. Figure 6 shows the force-displacement curves obtained in the experiment and simulation. 12 experiments were conducted. The standard deviation was minimal with an average of $1.7 \mathrm{kN}$ and can therefore not be seen in the graph.

In the experiment as well as in the simulation, the forces rise steeply at the beginning of the process, before plastic deformation of the workpiece starts and the forces rise in an even manner. At the end of the process, there is another

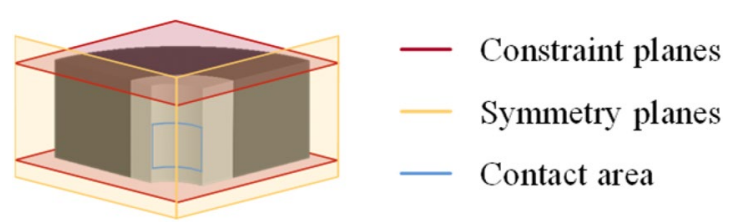

Fig. 5 Setup of die load simulation 


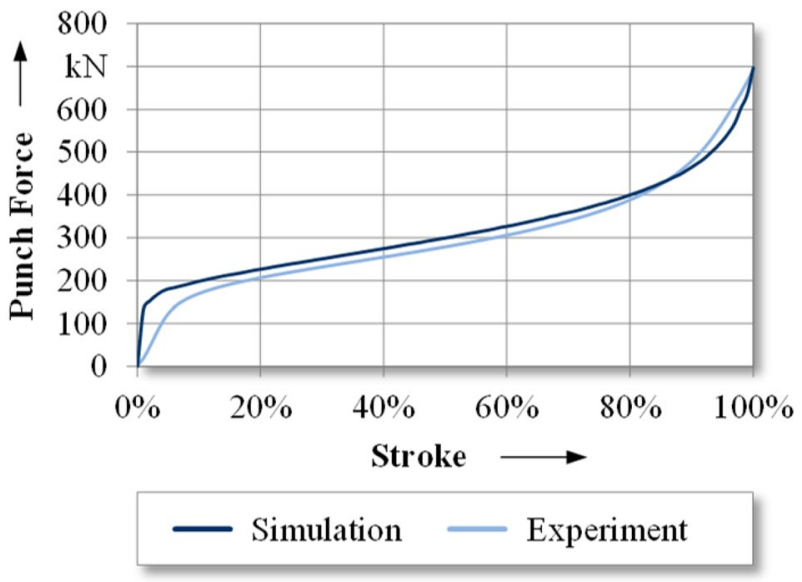

Fig. 6 Comparison of force-displacement curves for experiment and simulation according to [40]

sharp increase in force, because of the high friction and strain hardening when the die cavity is nearly completely filled. The curves show good agreement aside from slight deviations at the beginning of the process, which can be explained by the rigid modelling of the tools in the material flow simulation. Since the experiment was conducted forcecontrolled, maximum forces are roughly equal with 696.6 $\mathrm{kN}$ for the simulation and $691.2 \mathrm{kN} \pm 1.9 \mathrm{kN}$ for the experiment. In order to assess the resulting part geometries, five formed parts were measured using a topometric 3D sensor ATOS from GOM GmbH. The results were compared to the numerically derived part geometry, see Fig. 7.

The maximum geometrical deviation between simulation and experiment amounts to $0.318 \mathrm{~mm} \pm 0.045 \mathrm{~mm}$ and occurs at the far end of the ellipse. Taking into account the overall part dimension with a major half-axis of $15 \mathrm{~mm}$, this is a deviation of $2.12 \%$. Deviations in part height and width are lower than $0.2 \mathrm{~mm}$. The resulting geometries in the experiment and simulation are therefore in good agreement. During cold forging strain hardening occurs in the workpiece, increasing both the true strain and the hardness of the material. Therefore, these values are suitable for a qualitative

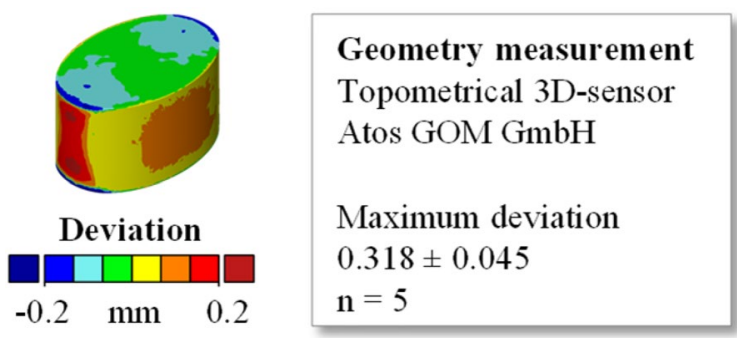

Fig. 7 Comparison of part geometry between experiment and simulation

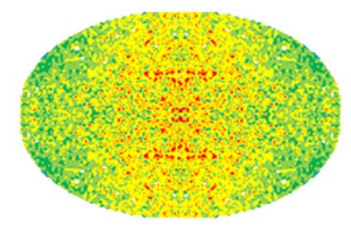

Hardness

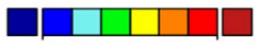

$200 \mathrm{HV} 0.05 \quad 350$

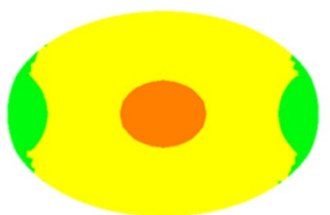

True Strain

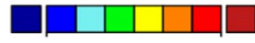

\section{Vickers Hardness measurement \\ Fischerscope HM2000 Resolution $200 \mu \mathrm{m}$ \\ Test force $500 \mathrm{mN} \quad$ Holding time $10 \mathrm{~s}$}

Fig. 8 Comparison of strain hardening between experiment and simulation

comparison to evaluate internal component properties [33]. The hardness measured according to Vickers with a resolution of $200 \mu \mathrm{m}$ and the true strain distribution in the middle of the simulated part are illustrated in Fig. 8.

Both graphs show an area of high strain hardening in the middle of the cross-section and lower strain hardening towards the major axis. In conclusion, the simulation results are in good agreement with the experiments. The material flow and the required forces are well represented by the simulation. Since these are the determining factors for the die load, the numerical model is qualified for the analysis of the occurring stresses in the die.

\section{Process analysis}

In order to provide basic understanding for the formation of local stress concentrations in the die, the stresses are analysed using the validated simulation model. This serves as a basis for the adaption of process stresses using stress pins. Figure 9 shows the development of tangential stresses and radial displacements scaled by a factor of 50. In a first step, the die is prestressed by the reinforcement ring, which exerts a constant pressure from the outside. Because of the elliptical inner contour of the die, prestresses and displacements are not distributed uniformly. The section at the $\mathrm{x}$-axis is displaced further resulting in a higher prestressing effect at the y-axis. This effect is overcompensated by the inner pressure from the workpiece in the process. During forming, workpiece and die are continuously in contact at the $\mathrm{x}$-axis, resulting in the highest displacements of the die there. At the end of the process, the die is being pulled apart in tangential direction at the y-axis. Because of that, there is a high level of tensile tangential stresses at the top of the die cross-section. 


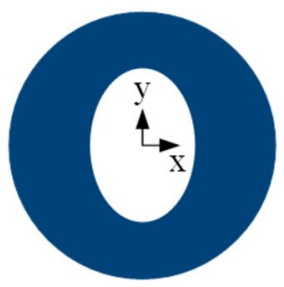

Die without load

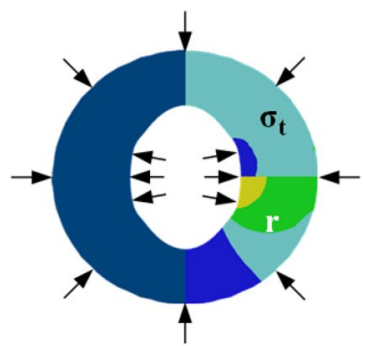

During forming

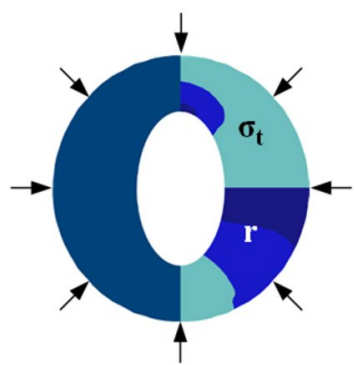

Prestress

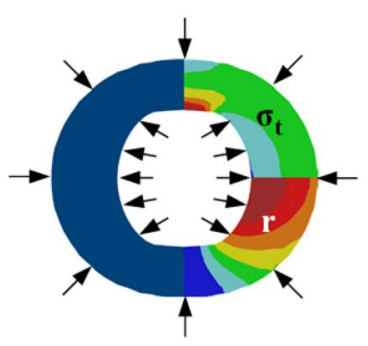

Process end

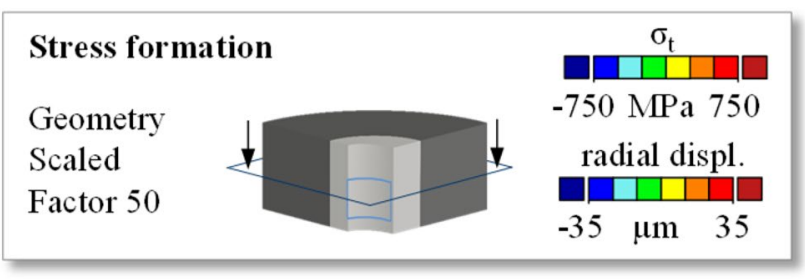

Fig. 9 Formation of process stresses in the model process

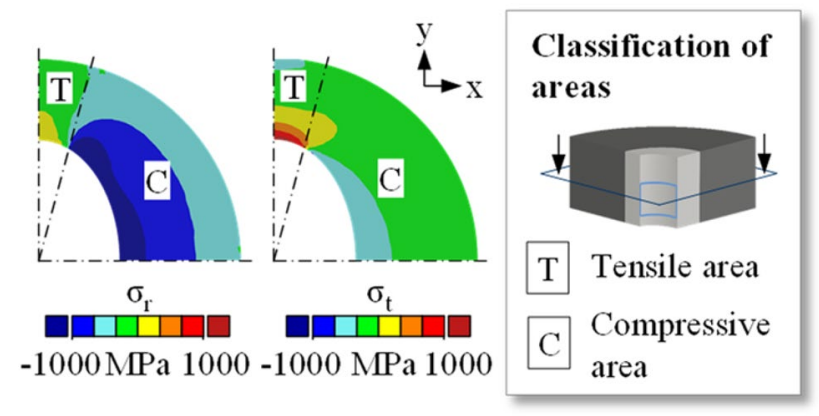

Fig. 10 Stress distribution under maximum load

It can be seen, that with maximum load at the end of the process, the stress state of the die is highly different around the $x$ - and $y$-axis. To illustrate this, Fig. 10 shows the radial and tangential stresses at the end of the process.

While there are significant tensile tangential stresses at the $\mathrm{y}$-axis, the area starting from the $\mathrm{x}$-axis is characterized by compressive radial stresses. The radial pressure from the workpiece in this area leads to the radial displacement and consequently the high tensile loads at the y-axis. The die can be separated into a tensile and a compressive area. As there are high radial displacements in the compressive area, it is critical for part accuracy. The high cyclic loading in the tensile area, on the other hand, is likely to initiate fatigue cracks. Taking into account the local stress state, local prestressing would have to focus on decreasing tangential stresses in the tensile area, while not increasing radial displacements in the compressive area. As a possibility to achieve this, the following chapter focuses on the use of stress pins for local prestressing.

\section{Analysis of stress pins for local prestressing}

The process analysis revealed that local loads occur in noncircular symmetrical tool geometries, so that a local influence on the stress state is necessary. To achieve this, the use of stress pins pressed into the die is analysed. Firstly, the stresses induced by the pins and their interaction with the die stresses are discussed. This enables the fundamental analysis of the local prestressing effect and the derivation of challenges for the application of stress pins. Secondly, the influence of position and parameters of the pins on the stress state is investigated in order to provide an understanding for their appropriate use. Since local tool loads also lead to locally increased radial displacements impeding part accuracy, the effect of stress pins on die displacement is analysed in the last step. A tool layout with stress pins and its assembly is illustrated in Fig. 11. Firstly, the die is produced with bores for the stress pins. Secondly, the stress pins are pressed into the bores creating a local prestress. The die is then inserted into the reinforcement ring to apply the global prestress. To meet the required tolerances the inner die contour is usually machined after the prestressing.

When pressing a pin into a bore, radial compressive stresses and tangential tensile stresses around the pin bore

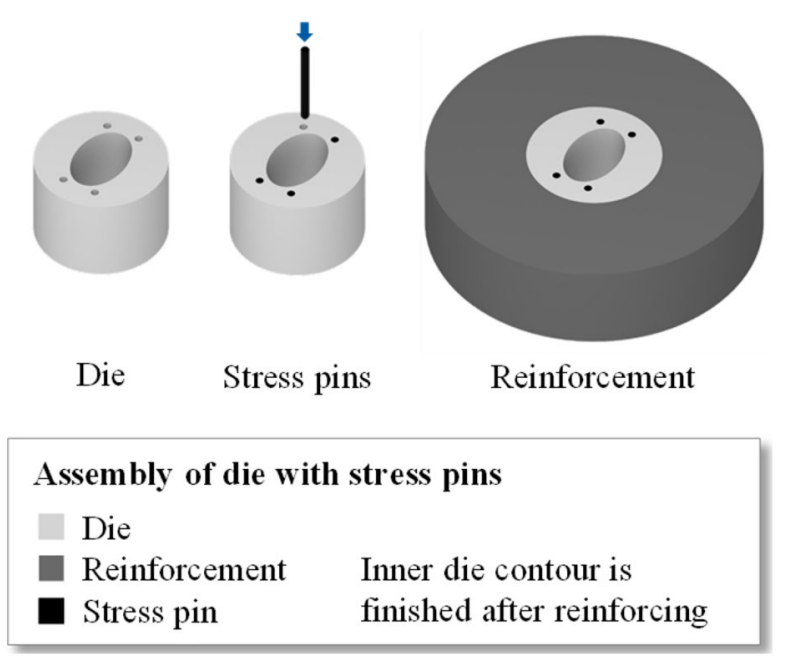

Fig. 11 Example for die assembly with stress pins 


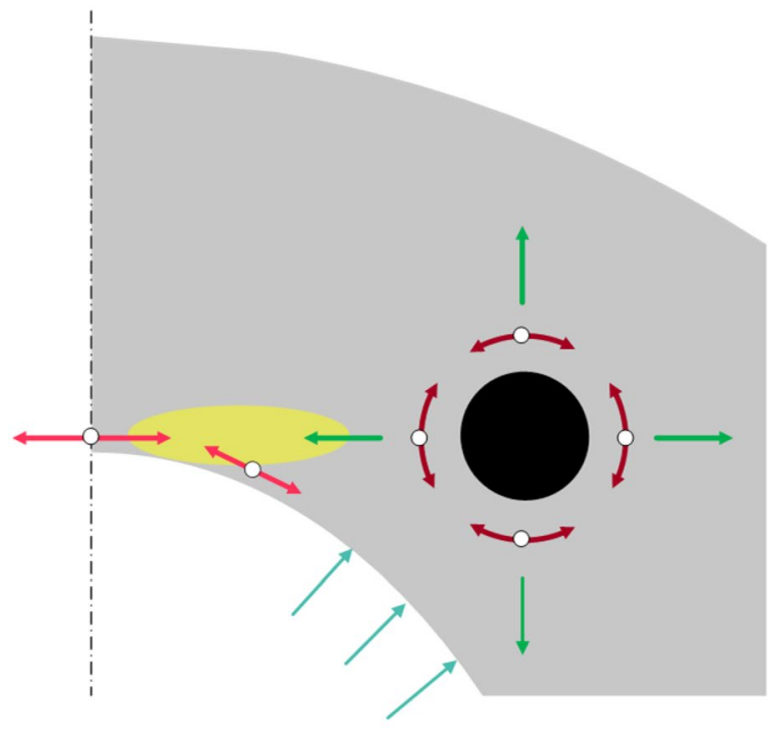

\section{Stress state with stress pin}

$\rightarrow$ Radial compressive process stresses

$\rightarrow$ Radial compressive pin stresses

$\leftrightarrow$ Tangential tensile process stresses

$\leftrightarrow$ Tangential tensile pin stresses Compensation of tensile process stresses through stress pins

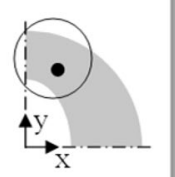

Fig. 12 Effect of stress pins

occur [41]. The pins should therefore be positioned so that the compressive pin stresses counteract the tensile process stresses. The principle of local prestressing through stress pins is illustrated in Fig. 12.

Because of the symmetry, only one pin is depicted. For an effective use, pins should be placed on both sides of the die. For further analysis, the pin is integrated in the numerical process model. A bore is inserted into the die and the pin is placed into the bore with a physical overlap corresponding to the required pin interference. Initially, a pin with a diameter of $\mathrm{d}=3 \mathrm{~mm}$ and an interference of $\xi=5 \%$ is positioned at a distance from the die surface of $\mathrm{a}=2 \mathrm{~mm}$ and an angle of $\beta=22.5^{\circ}$ measured from the $y$-axis. All of these parameters will be discussed in further detail in the following sections. In order to ensure joinability, the pin should be cylindrical and the pin material should have a certain level of ductility. Therefore, the high-speed steel HSS with a young's modulus of $210 \mathrm{GPa}$ is chosen from the simufact material database. The resulting model reflects two prestressing effects. Firstly, the local prestressing by the stress pin and secondly, the global prestressing by the reinforcement. In order to analyse each effect, the maximum principal stresses and minimum

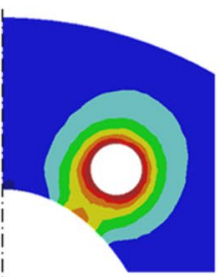

$\sigma_{\text {Max.PS }}$

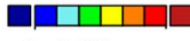

$0 \mathrm{MPa} 500$

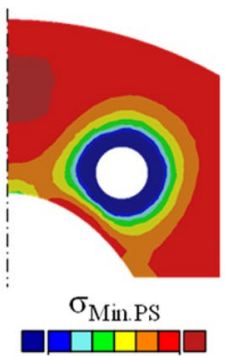

$-200 \mathrm{MPa} 0$

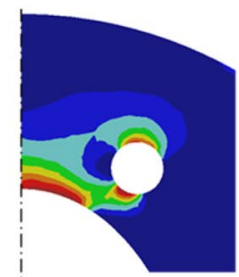

$\sigma_{\text {Max.PS }}$

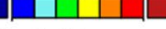

$0 \mathrm{MPa} 1000$

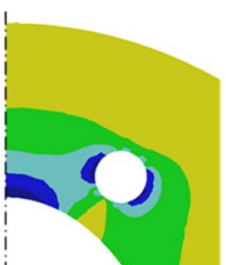

$\sigma_{\text {Min.PS }}$

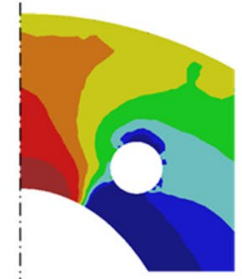

$\sigma_{\text {Min.PS }}$

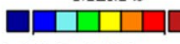

$-1000 \mathrm{MPa} 0$
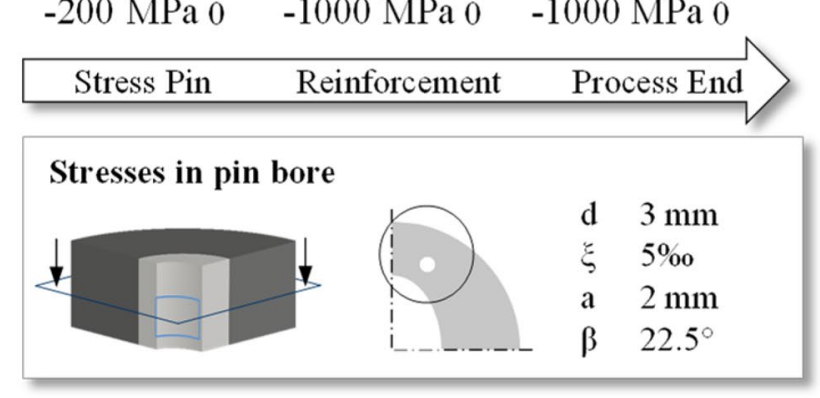

Fig. 13 Stresses development with use of stress pins

principal stresses are shown in Fig. 13, as they indicate the maximum tensile and compressive die loads, respectively.

In the tool production chain, the pin is first pressed into the die, resulting in a local prestress. Then the die with the pin is pressed into the reinforcement, creating a global prestress. During forming, process stresses overlap with the prestresses, creating the most critical load at the process end. As has been stated, the joining of the stress pin with the die leads to compressive and tensile stresses around the pin bore. The Minimum Principal Stresses caused by the pin show, that a local prestress of about $-100 \mathrm{MPa}$ is achieved in the critical area at the y-axis of the die. However, the tangential stresses around the pin influence the die surface, resulting in an increasing Maximum Principal Stresses at the position of the pin. In the second step, the local prestress by the pin is overlapped by the global reinforcement prestress. The reinforcement induces a tangential compressive stress, thus compensating the tensile stresses on the upper and the lower side of the pin bore. In this condition, there is a high compressive prestress at the critical tensile area. Minimum Principal Stresses show that the prestressing effect on the die surface at the position of the pin is decreased because 
of the tensile pin stresses. At process end, the separation into a compressive and tensile area is evident regarding the Minimum Principal Stresses with high negative values only occurring in the compressive area. As can be seen in the Maximum Principal Stress distribution, the process induces tensile stresses on the upper and lower side of the pin bore additionally to the tensile area. The bore is therefore subjected to cyclic loading. However, there is no contact with the workpiece at the pin bore, and fatigue failure usually originates at the die surface due to finishing or forming induced micro defects [42]. Therefore, the stresses at the surface of the die cavity are more critical. The following analysis will focus on how to use the compressive prestressing effect of the pins, without creating a negative effect of the tensile pin stresses on the die surface. According to the process analysis, the critical stresses at the tensile area occur in tangential direction. For this reason, the influence of the position and parameters of the pin on the tangential stress in the prestressing condition and at maximum process load are to be analysed. The varied parameters for the analysis are illustrated in Fig. 14.

The stress pins exert an inner pressure in the pin bore, which increases with the interference $\xi$. For thick-walled tubes with an outer diameter $d_{a}$ and an inner diameter $d_{i}$ under inner pressure $\mathrm{p}$, the formula for the radial stress distribution across the diameter $\mathrm{d}$ is as follows [43].

$\sigma_{r}=-p \cdot \frac{\left(\frac{d_{a}}{d}\right)^{2}-1}{\left(\frac{d_{a}}{d_{i}}\right)^{2}-1}$

According to this formula, the inner pressure $\mathrm{p}$ and the diameter of the pin bore $d_{i}$ would have an impact on the stress state of the surrounding die. Therefore, pin interference and diameter are analysed as parameters influencing the stresses exerted by the pin. The position of the pin is expected to affect the interaction with the process stresses and is analysed taking into account the shortest distance a from the surface of the die and the angle $\beta$ from the critical area. For a quantitative analysis, the minimum tangential
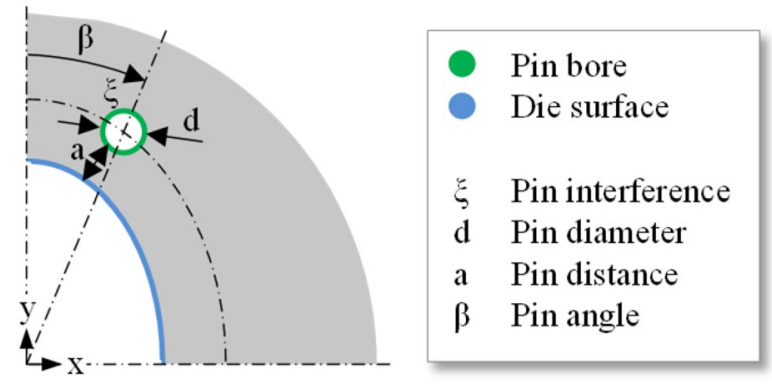

Fig. 14 Analysed parameters
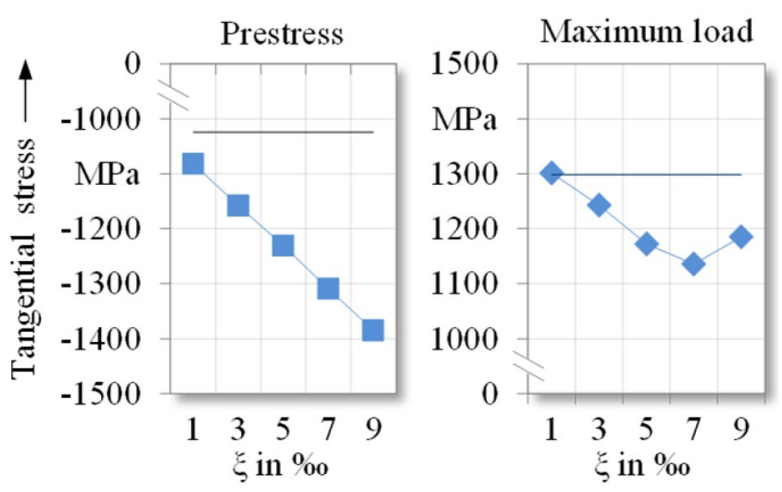

Fig. 15 Effect of stress pin interference on maximum tangential stresses

stresses occurring at the die surface during prestressing and the highest tangential stresses on the die surface at maximum load are analysed for each parameter. To further understand the stress development, stress distributions will be analysed for selected variants. Lastly, the influence of stress pins on part accuracy will be investigated via the radial displacement.

\subsection{Pin parameters}

Firstly, the influence of pin interference from 1 to $9 \%$ is analysed in five steps in Fig. 15. While 1\%o represents a very low local prestressing, pins with higher interferences than $9 \%$ are not expected to be joinable. The tangential prestresses show, that for all interferences the values with stress pins are lower than without them. With increasing interferences, the prestresses decrease in a linear manner
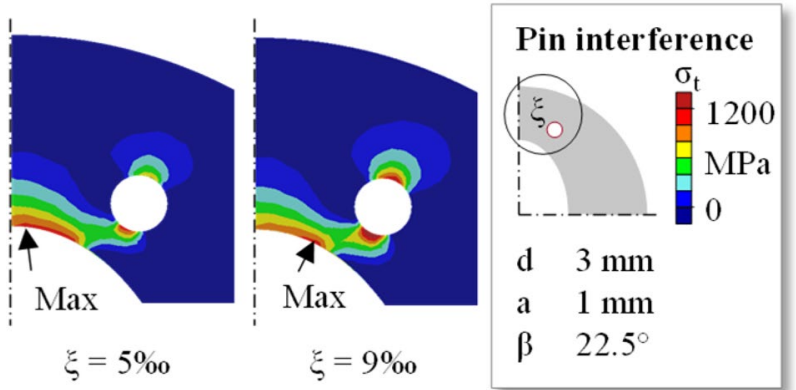

Fig. 16 Effect of stress pin interference on tangential stress distribution at maximum load 

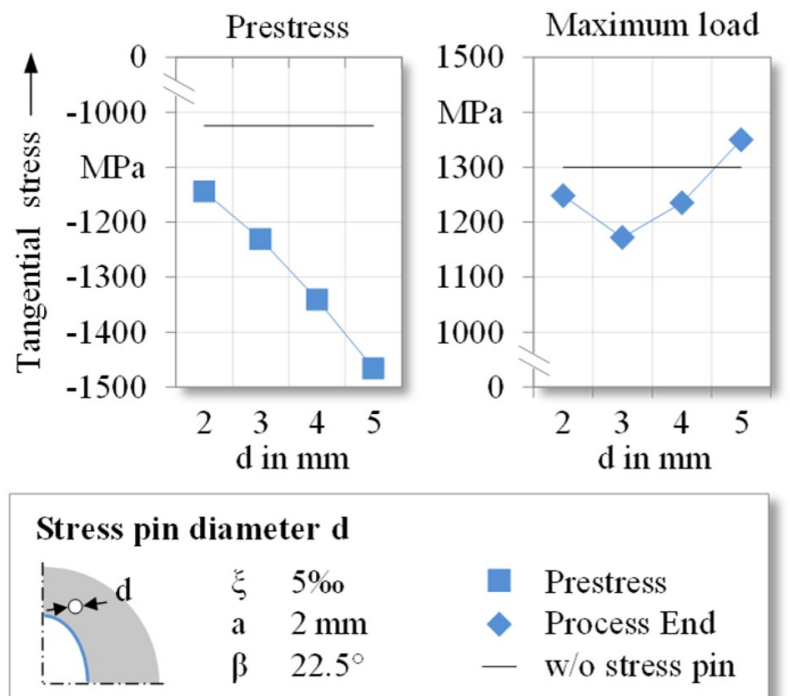

Fig. 17 Effect of stress pin diameter on maximum tangential stresses
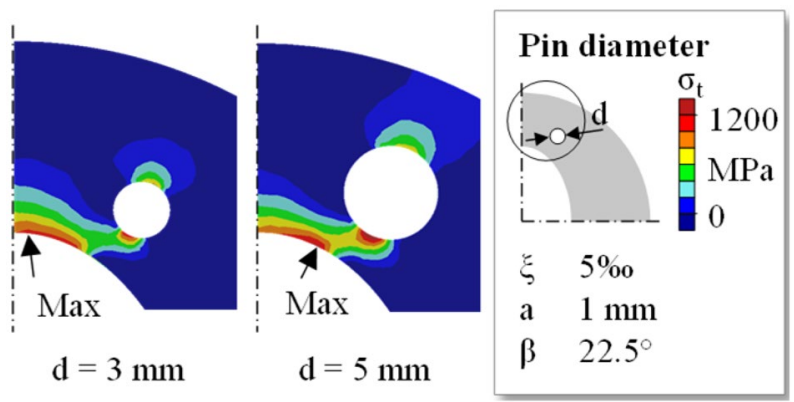

Fig. 18 Effect of stress pin diameter on tangential stress distribution at maximum load

from - $1082 \mathrm{MPa}$ for $1 \%$ to $-1385 \mathrm{MPa}$ for $9 \%$, because the inner pressure acting on the bore increases. The stresses at maximum load decrease continuously up to $7 \%$, before increasing again at $9 \%$. The lowest stress is reached with the interference $7 \%$ and a maximum tangential stress of $1136 \mathrm{MPa}$ compared to $1298 \mathrm{MPa}$ without pins.

The increase of the maximum stresses for $9 \%$ can be explained by the tangential stresses induced by the pin. With higher interferences, both compressive and tensile pin stresses increase. That means, that not only the beneficial impact of the pin on the critical area increases, but also the detrimental effect on the die surface at the position of the pin. This leads to a shift of the position of the highest tangential stresses from the $y$-axis toward the pin. To illustrate this, Fig. 16 shows the stress distribution under maximum load for $5 \%$ and $9 \%$.
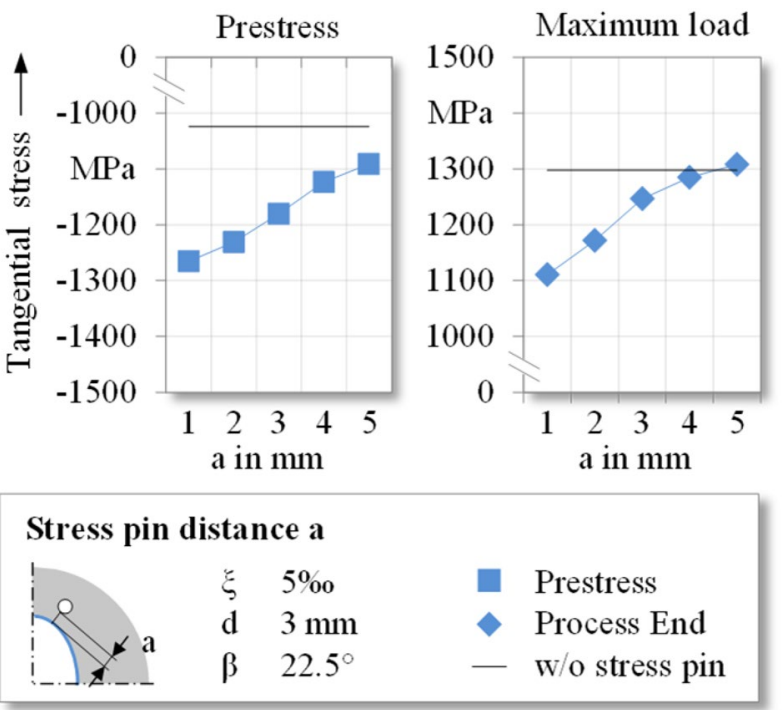

Fig. 19 Effect of stress pin distance on maximum tangential stresses

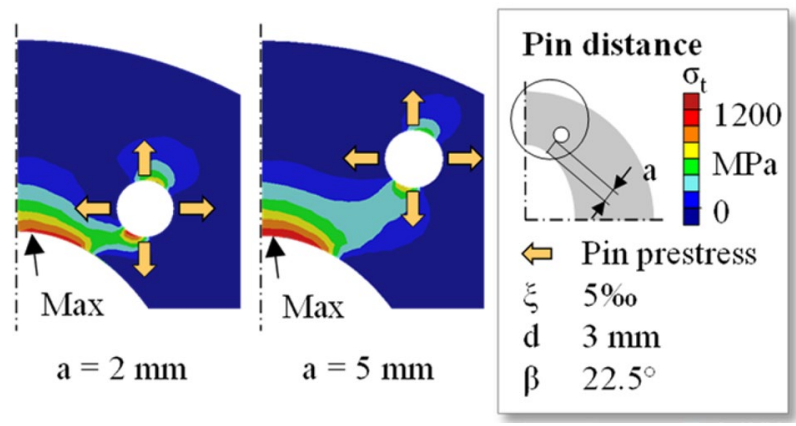

Fig. 20 Effect of stress pin distance on tangential stress distribution at maximum load

For 5\%, the maximum tangential stress on the die surface occurs near the y-axis. For $9 \%$, it is located near the position of the pin, since the pin stresses that influence the die surface increase. As a second pin parameter, the diameter of the pin is analysed in four steps from 2 to $5 \mathrm{~mm}$ in Fig. 17. Smaller pin diameters are not analysed, since the decreased resistance against buckling would lead to complications for the joining of the pins. According to Formula 1, an increasing pin bore diameter $d_{i}$ would result in higher compressive radial stresses occurring around the pin bore. For this reason, the effect of increasing pin diameters is similar to higher interferences, which increase the inner pressure in the pin bore.

Tangential prestresses are continuously decreased from - $1144 \mathrm{MPa}$ for $2 \mathrm{~mm}$ to $-1466 \mathrm{MPa}$ for $5 \mathrm{~mm}$. The stresses at maximum load decrease from $1248 \mathrm{MPa}$ for $2 \mathrm{~mm}$ to $1172 \mathrm{MPa}$ for $3 \mathrm{~mm}$, before increasing again up until the stresses for $5 \mathrm{~mm}$ with $1350 \mathrm{MPa}$ are higher than 
the value without pins of $1298 \mathrm{MPa}$. The reason is the higher pin effect for a diameter of $5 \mathrm{~mm}$, which results in a superposition of pin and process tensile stresses. This creates higher maximum stresses on the die surface at the position of the pin than at the y-axis. The effect is illustrated in Fig. 18.

\subsection{Pin position}

In order to evaluate the effect of the pin position, the shortest distance a to the die surface is analysed in 5 steps from a minimal value of 1 to $5 \mathrm{~mm}$ in Fig. 19. The lowest prestress of $-1265 \mathrm{MPa}$ occurs for a distance of $1 \mathrm{~mm}$. With an increasing distance, the effect of the pin decreases and prestresses come close to the value without pins of $-1024 \mathrm{MPa}$. Stresses at maximum load show the same trend. The lowest stresses occur for $\mathrm{a}=1 \mathrm{~mm}$ with $1111 \mathrm{MPa}$. The stresses then rise until $1308 \mathrm{MPa}$ for $\mathrm{a}=5 \mathrm{~mm}$.

An increasing distance to the critical area moves the stress pin to a less effective position for the local prestressing, as is illustrated in Fig. 20. It is notable, that in contrast to the parameters analysed before, a very close distance of only $1 \mathrm{~mm}$ does not negatively influence the stresses at the die surface. Pin diameter and interference are evidently more critical for this area. However, the small distance between die surface and pin bore might lead to problems regarding edge breakouts during joining.

The tangential distance of the pin to the critical area is analysed via the pin angle $\beta$ in Fig. 21. Five pin angles are evaluated from a close angle of $15^{\circ}$ to a remote angle of $45^{\circ}$. At $15^{\circ}$ the pin is already positioned at the tensile area, which

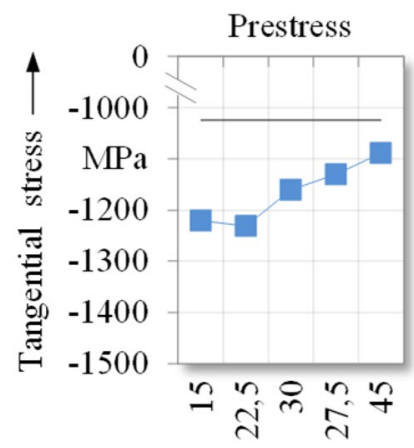

$\beta$ in $^{\circ}$

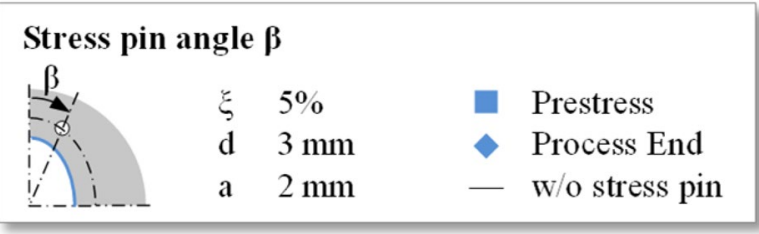

Fig. 21 Effect of stress pin angle on maximum tangential stresses

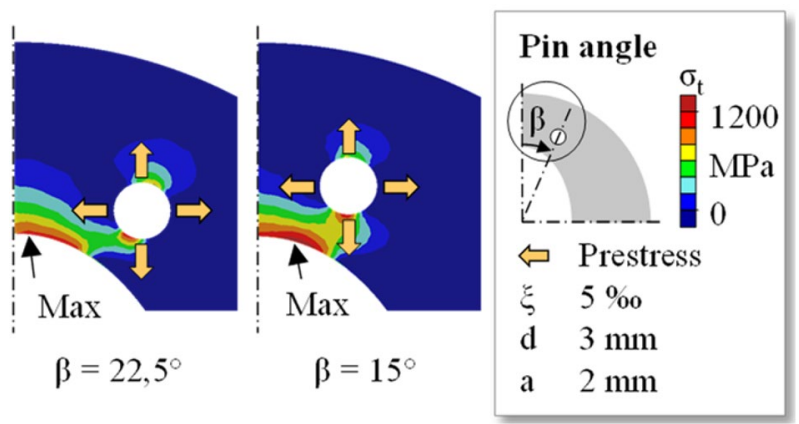

Fig. 22 Effect of stress pin angle on tangential stress distribution at maximum load

is why no lower angles are analysed. The prestresses decline with smaller angles up until $22.5^{\circ}$. From $22.5^{\circ}$ to $15^{\circ}$ the prestresses slightly rise from -1231 to $-1221 \mathrm{MPa}$. At $45^{\circ}$ prestresses amount to $-1089 \mathrm{MPa}$ compared to the value without pins of $-1024 \mathrm{MPa}$. It can be concluded, that stress pins have a small influence even from a distanced position. At maximum load, all angles except for $15^{\circ}$ show a decrease in stresses, with lower stresses occurring at lower angles. From $22.5^{\circ}$ to $15^{\circ}$ there is an increase in stresses from 1172 to $1352 \mathrm{MPa}$.

This increase indicates a negative influence on the die surface through the very close position of the pin to the critical area, as can be seen in Fig. 22. At $15^{\circ}$ the pin is positioned in the tensile area and thus creates higher tensile stresses at the pin position. The lower prestress for $15^{\circ} \mathrm{can}$ be explained by the higher distance to the critical area in $y$-direction. While the smallest distance to the die surface is constant at $2 \mathrm{~mm}$, the decreasing angle causes a higher distance in y-direction, thus impeding the prestressing effect. However, the negative influence on the die surface has a bigger impact than the slightly lower prestress due to the radial position.

\subsection{Radial displacement}

In the process analysis it was identified, that the local areas in non-axially symmetrical cold forging tools are critical

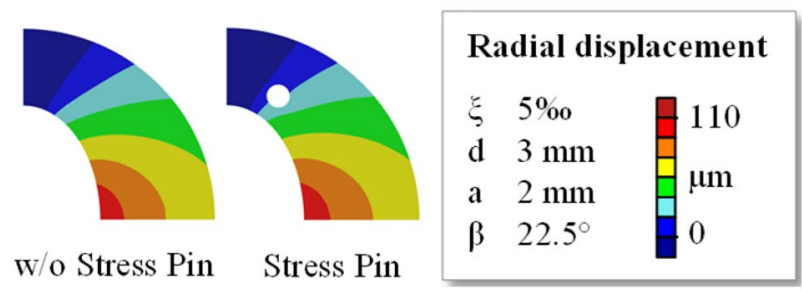

Fig. 23 Analysis of radial displacement with and without stress pin 


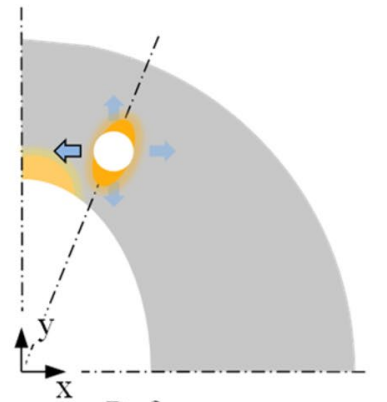

Reference
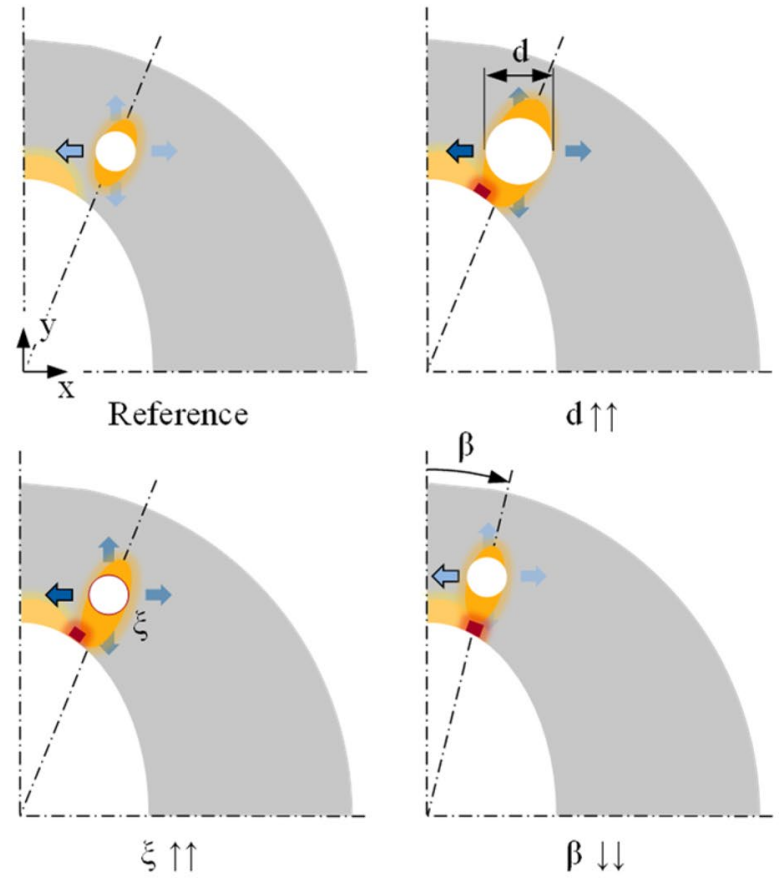

$\mathrm{d} \uparrow \uparrow$

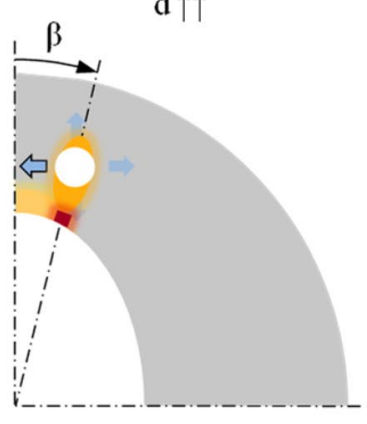

$\beta \downarrow \downarrow$
$\Rightarrow$ Pin compressive stress

$\Rightarrow$ Increased pin compressive stress

$\Rightarrow$ Local prestressing effect

Process tensile stresses

Pin tensile stresses

Superposition of tensile stresses

Fig. 24 Schematic illustration of the stress superposition of pin and process stresses

for tensile stresses causing fatigue and radial displacements impeding part accuracy. It was shown, that with appropriate design and positioning, stress pins positively influence the stress state. The radial displacements occurring in the process with and without stress pin are depicted in Fig. 23. It can be seen, that the distribution of radial displacements is equal for both variants. The reason is that, assuming equal Young's moduli for stress pin and die material, the rigidity of the die remains constant. Differences in the displacement during assembly of the pins are not taken into account, since the final form of the dies is usually machined after prestressing.

\section{Derivation of conclusions}

Cold forging is used for the production of increasingly complex part geometries. This poses challenges to the dies, as non-axially symmetrical geometries cause high local tool loads. The process analysis revealed, that tensile areas critical for fatigue failure occur as well as compressive areas with high displacements impeding part accuracy. In order to reach a more uniformly distributed and less critical stress state, a local influence is necessary. This can be achieved by the use of stress pins, which are pressed into the die causing a local prestress. Previous research has shown inconsistent results, both indicating the potential of stress pins, but in some cases showing a detrimental effect on the stress state [27]. Therefore, a fundamental understanding of the stress state caused by the pins is necessary in order to enable a beneficial use. Stress pins cause compressive stresses in radial direction and tensile stresses in tangential direction around the pin. The positioning and pin parameters have to be chosen so that the process stresses are compensated by the compressive pin stresses and not negatively influenced by the tensile pin stresses. Figure 24 schematically shows the influence of the stress state via pins and challenges for the design.

With an appropriate design, as is indicated in the reference variant of Fig. 24, compressive prestresses have a direct influence on the critical area without an interaction of the tensile pin stresses. While higher diameters and interferences increase the prestressing effect, they also increase tensile stresses, so that a detrimental superposition of tensile stresses can occur. In order to use the higher prestressing effect without the tensile interaction, pins with large diameters would have to be placed farther away from the tensile area. This in turn would impede the effectiveness of the prestressing. As has been suggested in [27], tools with large dimensions would be most suitable for an application of stress pins, since pins with higher diameters could be placed more flexibly. The prestressing effect by stress pins also increases by placing them nearer to the critical area. However, they still have to be positioned with a sufficient distance to the tensile area. A too close positioning will result in a negative influence of the stresses. Stress pins therefore are more suited for the use in tools with very localized tensile stresses. When there is a large area of tensile stresses, the pin placement would be limited to a great distance and the local prestressing effect decreased.

Generally, the flexibility of the pins regarding their position and interference allows applicability for a variety of complex tools without negatively influencing the part accuracy. However, careful process design is necessary to avoid a negative influence on the tensile stresses. 


\section{Summary and outlook}

The trend towards more complex part geometries causes local stress concentrations and fatigue failure in cold forging tools. To gain insights about the stress formation and research measures for the improvement of the stress state, a closed-die forging process for elliptical parts was designed. Local compressive and tensile areas occur in the die used in the process. To counteract the tensile stresses, the use of stress pins for a local prestressing was analysed. Pressing the pins into the die with an interference causes radial compressive prestresses, but also tensile tangential stresses around the pin. Though stress pins allow a very flexible influence on the stress state, careful process design is necessary to avoid creating new critical stresses. To illustrate the flexibility, further research work should focus on the application of stress pins for more complex part geometries. The influence of thermal effects on the die stresses would also be of interest. Furthermore, the effect of the improved stress state on tool life should be analysed experimentally.

Acknowledgements This research was supported by the Bavarian Research Foundation (BFS) within the scope of the project 1306-17 "Reinforcement systems for dies with non-circular symmetrical crosssections". The authors are grateful to the industrial partners from ZF Friedrichshafen AG, RIBE Verbindungstechnik GmbH and Penkert Metallverarbeitungs $\mathrm{GmbH}$ for their support in the project. Further thanks goes to ZWEZ-Chemie GmbH for the application of the lubricant and to the laboratory assistants and students supporting the execution of this work.

Funding Open Access funding enabled and organized by Projekt DEAL.

Open Access This article is licensed under a Creative Commons Attribution 4.0 International License, which permits use, sharing, adaptation, distribution and reproduction in any medium or format, as long as you give appropriate credit to the original author(s) and the source, provide a link to the Creative Commons licence, and indicate if changes were made. The images or other third party material in this article are included in the article's Creative Commons licence, unless indicated otherwise in a credit line to the material. If material is not included in the article's Creative Commons licence and your intended use is not permitted by statutory regulation or exceeds the permitted use, you will need to obtain permission directly from the copyright holder. To view a copy of this licence, visit http://creativecommons.org/licenses/by/4.0/.

\section{References}

1. Lange K, Kammerer M, Pöhlandt K, Schöck J (2008) Fließpressen - Wirtschaftliche Fertigung metallischer Präzisionswerkstücke. Springer, Berlin

2. Engel U (1996) Beanspruchung und Beanspruchbarkeit von Werkzeugen der Massivumformung. Meisenbach. ISBN 3-87525-072-9
3. International Cold Forging Group (2002) Tool life and tool quality in cold forging Part 1: general aspects of tool life ICFG document no. 14/02. Meisenbach Verlag Bamberg. ISBN 3-87525-162-8

4. Groche P, Moeller N, Hoffmann H, Suh J (2011) Influence of gliding speed and contact pressure on the wear of forming tools. Wear 271(9-10):570-2578

5. Skov-Hansen P, Bay N, Groenbaek J, Brondsted P (1998) Fatigue in cold-forging dies: tool life analysis. J Mater Process Technol 95(1-3):40-48

6. International Cold Forging Group (1992) General aspects of tool design and tool materials for cold and warm forging. In: International Cold Forging Group 1967-1992-Objectives, History Published Documents, Meisenbach, pp 33-58

7. Tekkaya A, Sonsöz A (1996) Life estimation of extrusion dies. Int J MechSci 38(5):527-538

8. Herbertz R, Hermanns H, Labs R (2013) Massivumformung kurz und bündig. Industrieverband Massivumformung. ISBN 978-3-928726-32-0

9. McCormack C, Monaghan J (2001) A finite element analysis of cold-forging dies using two-and three-dimensional models. J Mater Process Technol 118(1-3):286-292

10. VDI Verein deutscher Ingenieure e.V. (1999) VDI 3138, Blatt 2, Kaltmassivumformen von Stählen. Anwendung, Arbeitsbeispiele, Wirtschaftlichkeitsbetrachtungen für das Kaltfließpressen. BeuthVerlag, Berlin

11. Plančak M, Movrin D, Vilotić D, Car Z, Ivanišević A, Kačmarčik I (2012) An analysis of non-axisymmetric backward extrusion. Tech Gazette 19(4):953-957

12. Hsia S-Y, Shih P-Y (2015) Wear improvement of tools in the cold forging process for long hex flange nuts. Materials 8(10):6640-6657

13. Meissner R, Liewald M, Weiss A, Deliktas T (2019) Novel approach in cold forging for efficient manufacturing of shaft-hubassemblies. In: Proc. AIP Conference Proceedings, AIP Publishing LLC, 050024

14. Pale JA, Shivpuri R, Altan T (1992) Recent developments in tooling, machines and research in cold forming of complex parts. $\mathrm{J}$ Mater Process Technol 33(1-2):1-29

15. Engel U, Groenbaek J, Hinsel C, Kroiß T, Meidert M, Neher R, Räuchle F, Schrader T (2011) Tooling solutions for challenges in cold forging. In: UTF Science, Bd. 3, Meisenbach

16. Smolik J, Gulde M, Walkowicz J, Suchanek J (2004) Influence of the structure of the composite: 'nitrided layer/PVD coating'on the durability of forging dies made of steel DIN-1.2367. Surf Coat Technol 180:506-511

17. Andreas K, Henneberg J, Koch J, Merklein M (2016) Local adjustment of surface integrity of forming tools by adaptation of tool making process. In: Proc. Procedia CIRP, pp 339-342

18. Vilar R, Colaco R, Almeida A (1995) Laser surface treatment of tool steels. Opt Quantum Electr 27(12):1273-1289

19. International Cold Forging Group (2006) Tool life and tool quality in cold forging part 3: application of PM-steel and tungsten carbide material for cold forging tools-a comparison between Europe and Japan. Meisenbach Verlag Bamberg. ISBN 978-3-87525-242-2

20. Engel U (1997) Strength vs load - a general concept to estimate and to improve the reliability of tools in metal forming. In: Proc. International Conference on Industrial Tools, pp 43-50

21. Lange K, Hettig A, Knörr M (1992) Increasing tool life in cold forging through advanced design and tool manufacturing techniques. J Mater Process Technol 35(3-4):495-513

22. Groenbaek J, Nielsen EB (1997) Stripwound containers for combined radial and axial prestressing. J Mater Process Technol 71(1):S30-S35

23. International Cold Forging Group ICFG (1992) Calculation methods for cold forging tools. In: International Cold Forging Group 
1967-1992 - Objectives, History Published Documents, Meisenbach, pp 59-72

24. Groenbaek J (1992) Stripwound cold-forging tools-a technical and economical alternative. J Mater Process Technol 35(3-4):483-493

25. Groenbaek J (1996) Forming tool. United States Patent, 26th November 1996

26. Nagao Y, Knoerr M, Altan T (1994) Improvement of tool life in cold forging of complex automotive parts. J Mater Process Technol 46(1-2):73-85

27. Koc M, Arslan MA (2003) Design and finite element analysis of innovative tooling elements (stress pins) to prolong die life and improve dimensional tolerances in precision forming processes. J Mater Process Technol 142:773-785

28. Qin Y (2006) Forming-tool design innovation and intelligent tool-structure/system concepts. Int J Mach Tools Manufacture 46(11):1253-1260

29. Doege E, Bohnsack R (2000) Closed die technologies for hot forging. J Mater Process Technol 98(2):165-170

30. Osakada K, Wang X, Hanami S (1997) Precision forging of spline by flashless die forging with axially driven die. CIRP Ann 46(1):209-212

31. Bobzin K, Brögelmann T, Stahl K, Stemplinger J-P, Mayer J, Hinterstoißer M (2015) Influence of wetting and thermophysical properties of diamond-like carbon coatings on the frictional behavior in automobile gearboxes under elasto-hydrodynamic lubrication. Surf Coat Technol 284:290-301

32. International Cold Forging Group (1992) Lubrication aspects in cold forfing of carbon steels and low alloy steels. In: International Cold Forging Group 1967-1992 - Objectives, History Published Documents, Meisenbach, pp 93-103

33. Tekkaya A, Martins PA (2009) Accuracy, reliability and validity of finite element analysis in metal forming: a user's perspective. EngComput 26(8):1026-1055

34. Kim H, Yagi T, Yamanaka M (2000) FE simulation as a must tool in cold/warm forging process and tool design. J Mater Process Technol 98(2):143-149
35. Gröbel D (2017) Herstellung von Nebenformelementen unterschiedlicher Geometrie an Blechen mittels Fließpressverfahren der Blechmassivumformung. In: Franke J, Hanenkamp N, Merklein M, Schmitt M, Wartzack S (eds) FAU Studien aus dem Maschinenbau. FAU University Press, Erlangen. ISBN 978-3-96147-169-0

36. DIN 50106 (1978) testing of metallic materials - compression test at room temperature. Beuth-Verlag, Berlin

37 Hockett JE, Sherby OD (1975) Large strain deformation of polycrystalline metal at low homologous temperatures. J MechPhys Solids 23:87-98

38. Altan T, Ngaile G (2015) Double cup extrusion test to evalute lubricants for cold forging. In: Tekkaya AE, Homberg W, Brosius A (eds) 60 Excellent inventions in metal forming. Springer, Berlin, pp 325-329

39. Tekkaya AE (2005) A guide for validation of FE-simulations in bulk metal forming. Arab J SciEng 30(1C):113-136

40. Killmann M, Merklein M (2020) Analysis of the stress state in non-axially symmetrical cold forging dies. ProcediaManufact 50:307-313

41. Grote K-H, Feldhusen J (2011) DUBBEL: Taschenbuch für den Maschinenbau. Springer-Verlag, Berlin

42. Hänsel M (1993) Beitrag zur Simulation der Oberflächenermüdung von Umformwerkzeugen. Prozeßsimulation in der Umformtechnik, vol 6. Springer, Berlin, Heidelberg. ISBN 3-540-57251-1

43. Schwaigerer S (1970) Festigkeitsberechnung von Bauelementen des Dampfkessel-, Behälter- und Rohrleitungsbaues. Springer, Berlin

Publisher's Note Springer Nature remains neutral with regard to jurisdictional claims in published maps and institutional affiliations. 